\title{
ВСЕСОЮЗНАЯ НАУЧНАЯ СЕССИЯ, ПОСВЯЩЕННАЯ «ДНЮ РАДИО»
}

C 12 по 17 мая 1958 г. в Москве проходила очередная Всесоюзная научная сессия, посвященная «Дню радио», созванная Научно-техническим обществом радиотехники и электросвязи им. А. С. Попова.

В работе сессии принимали участие работники вузов, научно-исследовательских институтов Государственного комитета Совета Министров СССР по радиоэлектронике, Министерства связи и Академии наук СССР, предприятий радиотехнической промышленности, а также зарубежные специалисты, представители научно гехнической общественности Болгарии, Венгрии, ГДР, Польши, Чехословакии Югославии, США, Франции, ФРГ, Анілии, Швеции и Финляндии.

На сессии было заслушано около 280 докладов о результатах научно-исследовательских и практических работ в области радиоэлектроники, проведенных в вузах, научно-исследовательских организациях, конструкторских бюро и предприятиях Москвы, Ленинграда, Қиева, Харькова, Таганрога, Томска, Горького и других городов страны.

Сессию открыл председате.ль Центрального Правления обшества чл.-корр. АН СССР В. И. Сифоров.

На пленарных заседаниях участникІт сессии заслушали доклады: чл.-корр. $\mathrm{AH}$
СССР Б. М. Вула «Лавинные дроцессы в полупроводниках»; докт. техн. наук Л. А. Жекулина «Исследование ионосферы с помощью ракет и искусственных спутников Земли»; акад. А. А. Лебедева и канд. физ.-мат. наук ‥ M. Кушни. ра «Современные электронные микроскопы»; докт. физ.-мат. наук Н. Г. Басова «Квантовая раднотехника».

На секции теории информации было заслушано 25 докладов. Уровень представленных докладов свидетельствует о значительно возросшей активности научной мысли в области теории информации. Темы доктадов 'характеризуются широким охватом различных проблем, включаюцих теорию эффективного кодирования, теорию потенциальной помехоустойчнвости, вопросы сжатия спектров сигнала, практические вопросы построення запоминающих устройств и др.

В значительном числе докладов рассматривались задачи теории информации B примен нии $\mathrm{k}$ каналам $\mathrm{c}$ переменными параметрами, что является дальнейшим шагом в развитии теорин.

В докладе В. И. Сифорова «О пропускной способности однолучевых и многолучевых каналов связи» было приведено условие получения высокой пропускной способности канала с многолучевым распространением волн при низ- 
ком уровне аддитивных помех. Показано, что однолучевые каналы со случайным изменением поглоцения имеют весьма высокую собственную пропускную способность.

Доклад Ф. П. Тарасенко «Об информационном подходе к методам приема» был посвящен одной из практически важных задач теории связи - отысканию наилучшего метода приема (при заданных условиях и по заданному критерию).

Л. И. Филиппов рассмотрел потенциальную помехоустойчивость иделльного радиоприемного устройства выявления сигналов для случая системы связи с дискретными ортогональными сигналамн.

В докладе Д. А. Новика «Система пе. редачи электрических сигналов оптимальным кодом Шеннона-Фано» был рассмотрен технический метод осуществления операпни перекодирования сигналов и некоторые особенности неравномерного двоичного кода Шеннона-Фано в классе дВончных кодов.

В цокладе А. Е. Башаринова и Б. С. Флейнимана «Применение метода послецовательного анализа в устройствах обнаруження слабых сигналов в лиумах» была предложена методика для измерения функции распределения длительности процесса накопления с анализатором последовательного типа и приведены экспериментальные данные измерений.

Л. $M$. Фннком в докладе «O потенциальной помехоустойчивости при неопределенной фазе сигнала» были выведены неравенства, выражающие оптимальный критерий приема дискретных сообщений при флюктуационной помехе, когда начальная фаза высокочагтотного заполнеІия сигнала является случайной величиной

Діоклад В. А. Каширина и Г. А. Шустовой «Оптимальные по помехоустойчивости параметры систем телеизмерения» был посвящен определению помехоустойчивости передачи сигналов телеизмерения лия амплитудной, частотной, частотнонмпульсной и кодовой модуляций при слабых и относительно сильных флюктуационных помехах.

Б. С. Флейшман рассмотрел вопрос о построении оптималыного в смысле Шениона кода в случае бинарного симмет ричного канала.

В докладе Л. Ф. Бородина «Метод построения некоторых кодов с простым основанием» были рассмотрены регулярные методы построения систематических кодов, корректирующих одиночные ошибки.

К. А. Мешковский на основе принципов построения помехоустойчивых кодов произвел построение одного класса оптимальных кодов и показал его особенности.

Секция электроники заслушала более 20 докладов, посвященных теоретическим и экспериментальным исследованиям электронных приборов.

В докладе «Широкополосные электрон- но-лучевые трубки для наблюдения и регистрации электрических импульсов и колебаний СВЧ» П. А. Тарасов рассмотрел характеристики трубок, пригодных для регистрации быстрых колебательных процессов сантиметрового диапазона.

Доклад В. П. Радченко был посвящен вопросу практического использования ламп с катодной сеткой.

В докладе Г. Ф. Семенова, В. П. Сазонова, М. М. Сбитневой и А. С. Бондарева «Применение зонда с высокоомной подводкой для исследования электромагнитных полей в резонаторах и волноводах» были доложены результаты экспериментов, которые позволяют проверить выводы теоретического расчета замедляющих систем и могут быть использованы при расчете эквивалентных параметров плоских неоднородностей в волноводе.

В. В. Бакакина выступила с докладом «Применение диффузного метода для резонансных разрядников».

М. И. Кузнецов, В. А. Бербасов и Л. П. Боброва посвятили свой доклад «Флюктуационный процесс в неразрезном магнетроне» описанию некоторых конструкиий шумовых магнетронных генераторов сантиметрового днапазона.

Ю. А. Кацман в докладе «Отбор колебательной энергии от электронного потока, модулированнсго по плотности» указал, что теорема эквивалентности дает основание для рассмотрения процесса отбора энергии в общем случае любой конфнгурацик электрического поля, взаимодействующего с потоком.

В докладе М. Б. Голанта «Отражательный клистрон с широким диапазоном электронной настройки» был рассмотрен способ расцирения диапазона электронной настройки путем использования трех пролетов электронов через высокочастотный зазор.

Н. И. Иткин, Е. С. Евтифеева и Н. П. Антоненко рассмотрели преимущества радиорелейного отражательного клиетрона, являющегося экономичным прибором простой и дешевой конструкции

В докладе О. И. Орнатской и С. Г. Афанасова «O работе электронного промежутка в режиме возврата при больших амплитудах высокочастотного поля» были прнведены экспериментальные данные генераторов дециметрового диапазона, использующих диодный промежуток для электронной перестройки.

С. И. Бычковым были приведены качественные объяснения явления электронного смещения частоты и дано приближенное описание частотных свойств магнетрона в режимах больших амплитуд колебаний.

M. И. Кузнецов и В. Е. Нечаев посвятили свой доклад вопросу экспериментального изучения колебаний типа вра. щающейся волны в неразрезном магнетроне.

В докладе А. И. Терещенко «Влияние различных факторов на критическое маг- 
нитное поле магнетрона с сеткой» был дан анализ физической картины работы сеточного магнетрона и приведено comoставление теоретических и экспериментальных данных.

В докладе В. П. Шестопалова «Исследование замедляющей системы с лвумя спиралями, помещенными в диэлектрнческую среду» было рассмотрено влиянис спиралей и днэлектрика на распределение потока энергии в замедляюцсй системе.

А. С. Tarep и В. А. Солнцев рассмотрели вопрос о распространении малого иысокочастотного сигнала в электронных потоках с периодически изменяюцейси скоростью электронов.

В докладе Я. $M$. Туровера «Теорня и расчет плавных переходов» был показан способ создания плавных переходов» при сильных и слабых неоднородностях связи.

В докладе И. Ш. Белуга были приведены соображения относительно определения волновой проводимости, входящей в уравнение дисперсии штыревой замедяяюццй системы, сопротивления связи и амплитуд пространственных гармоник

Результаты исследований тонкопленочных спиральных поглотителей для ЛБВ были доложены В. В. Слуцкой

На секции передающих устройств (ру ководитель проф. $M$. С. Нейман) было заслушано около 20 докладов.

В докладе 3. И. Моделя и Н. С. Фузик была развита приближенная эквивалентпая схема лампового генератора и получены основные соотношения в ней для различных режимов работы.

Г. А. Зейтленок в докладе «К теорни усилителя мощности по схеме с обшсі сеткой» рассмотрел вопросы устойчивости усилителя и дал метод расчета его режима.

В докладе А. И. Лебедева-Карманова «Современные телевизионные радиостан. ции» была дана характеристика отечественных и зарубежных достижений в отношении габаритных и энергетических показателей телевизионных радиостанций и высказаны соображения о принципах наиболее рационального построения шкалы мощностей передатчиков.

Г. 3. Бесидский сформулировал общие технические требования, предъявляемыс к оборудованию автоматизированных ве щательных радиостанций, в частности УКВ диапазона.

В. М. Қатушкина и 3. И. Модель в докладе «Мостовые методы сложения мош. ностей нескольких генераторов» на основе экспериментальных исследований многополюсных УҚВ мостов показали, что наиболее удачным варнантом является сочленение квадратных мостов.

В докладе С. И. Бычкова «Переходные процессы при импульсной работе магнетрона на несогласованный фидер. был установлен общий характер протекания переходного процесса и выяснено влияние длины передающей линии, сте- пени рассотаacoвâHig нагрузки, величины связі гезератора с іинлей и фазы первого стражения.

В своем докіладе С. Г. Афанасов и П. М. Бубнов рассмотре.п конструкции триодных генераторов дениметрового диапазона, в которых в качестве колебательных контуров нсполізуотся отрезки пиний передачи с периодически пзменяюпимися параметрами.

В докиаде Чжан Цунь-чжина «О требованиях, предъявляемых $к$ частотно-фазовым характернстикам высокочастотной части канала связи прІІ испо.льзовании оптиманіной амплитудно-фазовой модуઔяции» была дана количественная оценка в. ияния частотных іा фазовых искажениї ла нелинейные искаження 2.7я случая линейного детектирования.

В. П. Демешин рассказал о cпocoóe улравиения $R C$-генератора с помоцью элемента, сбладающего линейно-томаной характеристнкой.

В докладе Қ. Н. Бурмистрова «Неиоторые вопросы временной нестаб̆нтьност:! кварцевых резонаторов» были приведечы результаты нсследований и дан ана.lиз ()акторов временной нестабнтьностн.

В. С. Андреевым были рассиотренд особенности іl достониства регенератненьіх делитсіё̆ частоты по сравнен!ю : другими типами делителей частоты почт: синусоидальных колебаний.

M. Н. Мерзлякова. 3. М. А.тексеева. К. Н. Важенин и В. Н. Детинко рассмот. реги вопрос о причинах ухода частоты и амплитуды автогенераторов на по.тпроводниковых трнодах и предложнли простой метод термостабитнации в широком интервале тсмператур.

Доктад Я. К. Трокименко б́ыт посвящен об́ласти применения и схемному вb:полиению однокаскадных цепочечных $R C$ генераторов синусоидального напряже. ния на плоскостных трнодах.

А. С. Майдановским бы. рассмотрена работа автогенератора на по.тпроводніковом триоде с зазем.тенной Јазой при воздействии па него виешней талмсниче. ской силы.

Секция общей раднотехнй застушапа свыше 25 докладов. З:гчите-ьное количество нз них было посзямено вопросам теории цепей ц1 Łеорй йлео́аний. Особо следует отметить вледісшие доклады: Э. В. Зеляха. в котором о́ыли изложены основы рәзработанғой докладчн. ком теорни автоно:тьх четьрехполюснн ков; С. И. Тететьбау «а «O компенсацин искаженнй ІІ о предв:скажениях», в котором была рассмотуе:а оошая постановка задачи комгенсацин іслажений, создаваемых преобразователем ннформацин и приведен ряд при:.есов (частотные и нелинейнье предыскалени, совместимая оптнмальная однополосная передача с несущей, объемная рентгенография и др.).

А. .7. Фельдштейна «О минимальном числе параметров, определяющем пассивный четырехполюсник», в котором была 
предпринята попытка уточнения вопроса - минимальном числе параметров четырехполюсника, основываясь на понятиях и терминах волновых матриц; В. Г. Қарпова «Переходные процессы в нелинейных апериодических системах и некоторые их практические прнложения», в котором были изложены методы анализа переходных процессов в нелинейных цепях.

По разделу теории колебаний, в докладе Г. Ш. Кеванишвили «К теории нели нейных колебаний в радиотехнике» был изложен метод решения нелинейных дифференциальных уравнений, представляющий развитие метода медленно меняющихся амплитуд.

Л. Н. Қапцов рассмотрел особенности процесса установления стационарных автоколебаний в автогенераторах на полупроводниковых триодах.

В докладе И. Г. Акопяна были доложены результаты исследований процессов в автогенераторе, находящемся под воздействием флюктуационных помех и синхронизируемом малой синусоидальной силой с частотой, близкой к собственной частоте автогенератора.

В докладе И. Н. Важенина, А. С. Майдановского и В. Н. Детинко была рассмотрена нелинейная теория автогенераторов на полупроводниковых триодах $\mathrm{c}$ заземленной базой с индуктивной и емкостной обратными связями.

На секции полупроводниковых приборов было заслушано около 20 докладов и сообщений.

В докладе А. В. Красилова, Е. С. Сальтыкова и А. Б. Полякова были приведены данные о выпускаемых у нас и за рубежом мощных полупроводниковых триодах.

В докладе «Кремниевые выпрямительиые диоды» Г. А. Зеликман рассмотрел существующие типы отечественных кремниевых диодов средней мошности и перспективы их развития.

Доклад А. С. Сущик был посвящен состоянию разработки полупроводниковых аналогов стабиливольтов на основе кремния.

В докладе Э. И. Адировича и А. Ю. Гордонова был проведен расчет частотной и переходной характеристик уснлительного каскада на полупроводниковом триоде по схеме с общей базой.

T. М. Агаханян посвятил свой доклад рассмотрению переходной характеристики коэффициента передачи тока дрейфового триода. Было приведено приближенное выражение переходной функции коэффициента передачи, которое можно использовать также для расчетов частотных и фазовых характеристик.

В докладе Б. Н. Қононова «Переходные процессы в симметричных триггерах на плоскостных полупроводниковых тркодах» на основе анализа переходных процессов определены оптимальные параметры триггера, при которых схема об- ладает максимальной частотой переключения.

Б. А. Кузьмин в докладе «О работе полупроводниковых триодов в области насыщения» рассмотрел физические процессы, происходяцие в типовой переключающей схеме с общей базой в режиме насыщения.

Ю. М. Азьян и Е. Я. Сенаторов рассмотрели вопрос о влиянии особенностей переходных характеристик на работу схем с полупроводниковыми триодами. Докладчики отметили, что вид переходной функции существенно зависит от величины тока смещения эмиттерного перехода в области его малых значений.

На секции антенных устройств значительный интерес вызвали доклады, рассматривающие применение ферритов в современной волноводной технике и дифракционные задачи.

В докладе «Об отражении и преломлении электромагнитных волн на границе воздух - феррит в прямоугольном волноводе» А. А. Пистолькорс и М. Л. Маршак отметили, что при малых намагниченностях феррита на величине коэффициента отражения основной волны $\mathrm{H}_{10}$ практически не сказываются высшие типы воли.

Д. Н. ПІокусин рассмотрел вопрос о решении системы дифференциальных уравнений в частных производных, вытекающей из уравнений Максвелла, для случая поперечного намагниченного прямоугольного волновода, заполненного ферритом.

В докладе В. А. Хромова и Г. Л. Сучкина «Тепловое электромагнитное излучение систем, не подчиняющихся теореме взаимности в диапазоне сверхвысоких частот» были приведены результаты экспериментального псследования на ферритовом резонансном изоляторе.

А. А. Пистолькорс н М. Л. Маршак рассмотрели вопрос о прохождении электромагнитных волн через ферритовую пластинку в вольноводе в зависимости от напряженности внешнего магнитного поля при разных значениях толщины пластинки и электрической проницаемости феррита.

В докладе В. А. Қаплуна, Л. В. Князевой и А. А. Пистолькорса методом Кирхгофа была исследована дифракцня у диэлектрического или потупроводящего листа и выведены выражения, справедливые для точек, достаточно удаленных ог краев и поверхности листа.

В докладе «Электромагнитные поля в штыревых замедляющих системах» $Л$. А. Любимов рассмотрел метод точного вычисления электрических и магнитных по лей в замедляющих системах типов односторонних и встречных штырей.

Около 15 докладов было сделано на секции распространения радиоволн.

В докладе Г. В. Букина была описана установка для вертикального зондирования ионосферы, при помощи которой проводились наблюдения на борту дизель- 
Электрохода «Лена» за время перехода в Антарктику и в поселке Мирный.

Р. А. Зевакина осветила в своем докла де некоторые особенности ноносферных возмушений в высоких широтах; были приведены результаты анализа ионосферных возмущений, зарегистрированных в Мурманске в 1954-1956 гг. и рассмотрен вопрос об использовании полученных результатов для оперативного обслуживания радиосвязи в высоких широтах.

В докладе Г. Е. Левитского «Некоторые вопросы теории распространения УКВ над неоднородной поверхностью земли» был предложен приближенный метод решения задачи о дифракции радиоволн на кусочно-однородной поверхности.

В докладе «Радиолокационные наблюдения метеоров в Томске» Ф. И. Перегудов привел описание установки, сконструированной в Томском политехническом институте для радиолокации метеоров и допожил о результатах наблюдений за 1957-1958 гг.

В докладе Б. С. Дудник на ту же тему было отмечено, что для исслелования метеоров целесообразно использовать радиоволны длиной 4-12 метров. Докладчик рассказал о разработанном комплексе аппаратуры, позволяющей, проводить радиотокационные наблюдения на волне $8,13 . M$.
К. М. Косиков до.ожил о разработанных способах практического применения на радиотрассах большой протяженности наклонно-возвратного зондирования на одной частоте. Докладчик указал, что данная методика позво.ли.та в 1958 г. применить наклонно-возвратнос зондирование в помошь эксп.уатацин радиосвязи и радиовешання

В докладе К. М. Коснкова и В. Н. Трунова была дана эмпирпческая формула для расчета коэффициента перекрестной модуляции в зависнмости от параметров передатчнков и от их территориального разноса.

В докладе Г. М. Бартенева, на основании статистической обработки результатов измерений 12-ю поносферными станциями критических частот ноносферы с 1933 по 1955 гг. была чис.тенно определена зависимость между однннадцатилетним циклом солнечной деятельности и степенью ионизации атмосферы.

В. И. Михайлов рассмотре.т вопрос о рассеянии электромагнитных волн на турбулентных пульсаниях, с учетом вихря средней скорости, кақ прчины дальнего распространення радиоснгналов.

Ряд интересных докладов б́.. заслу. шан на секции телевидения.

На заключительном пленарно: заседании 17 мая с приветствиямн вьступили представители зарубежных делегашй. 